\title{
Analysis of the Prevalence of Ventricular Late Potentials in the Late Phase of Myocardial Infarction Based on the Site of Infarction
}

\author{
Paulo Roberto Benchimol Barbosa, Marcos Oliveira de Sousa, Eduardo Correa Barbosa, \\ Alfredo de Souza Bomfim, Paulo Ginefra, Jurandir Nadal
}

Rio de Janeiro, RJ - Brazil

\begin{abstract}
Objective - The initial site of myocardial infarction (MI) may influence the prevalence of ventricular late potentials (VLP), high-frequency signals, due to the time course of ventricular activation. The prevalence of VLP in a period of more than 2 years after acute MI was assessed focusing on the initially injured wall .
\end{abstract}

Methods - The prevalence of VLP in a late phase after MI (median of 924 days) in anterior/antero-septal and inferior/infero-dorsal wall lesion was analyzed using signalaveraged electrocardiogram in time domain. The diagnostic performance of the filters employed for analysis on was tested at high-pass cut-off frequencies of $25 \mathrm{~Hz}, 40 \mathrm{~Hz}$ and $80 \mathrm{~Hz}$.

Results - The duration of the ventricular activation and its terminal portion were larger in inferior than anterior infarction, at high-pass cut-off frequencies of $40 \mathrm{~Hz}$ and $80 \mathrm{~Hz}$. In patients with ventricular tachycardia, these differences were more remarked. The prevalence of ventricular late potentials was three times greater in inferior than anterior infarction.

Conclusion -Late after myocardial infarction, the prevalence and the duration of ventricular late potentials are greater in lesions of inferior/infero-dorsal than anterior/antero-septal wall confirming their temporal process, reflecting their high-frequency content.

Key words: signal-averaged electrocardiogram, myocardial infarction, ventricular arrhythmia

Hospital Universitário Pedro Ernesto - UERJ e Instituto Luiz Alberto Coimbra de Pós-Graduação em Engenharia - UFRJ

Mailing address: Paulo Roberto Benchimol Barbosa - Rua Pompeu Loureiro, 36/702 22061-000 - Rio de Janeiro, RJ, Brazil - E-mail: ecgar@ecgar.org

English version by Stela Maris C. e Gandour
Ventricular late potentials are low-amplitude high-frequency signals originating in damaged regions of the ventricular myocardium, where the conduction of electrical stimuli occurs in a slow and fragmented manner. Ventricular late potentials are markers of reentry ventricular arrhythmias ${ }^{1-3}$. Due to the low velocity of conduction, these potentials exceed the duration of ventricular activation and are detected in the ST-segment. The use of statistical techniques, in which 2 to 3 hundred sequential QRS complexes detected on the body surface are independently coherent-averaged, allows amplification and identification of these signals because of the reduction in the intensity of the instrumentation noises ${ }^{4-7}$.

The identification of ventricular late potentials in patients with a transmural myocardial infarction is of major interest ${ }^{3,8-10}$. The myocardial remodeling process that follows transmural myocardial infarction is characterized by fibrosis, redistribution of fibers in the injured region, and residual metabolic alterations not only plays a major role in segmentary myocardial function but also provides a favorable environment for the development of reentry circuits ${ }^{11}$.

Considering these markers, preliminary studies suggest that transmural myocardial infarctions involving the inferiorinferodorsal wall have a higher prevalence of ventricular late potentials than those involving the anterior-anteroseptal wall. These findings are based on differences related to the start of electrical activation in the affected regions ${ }^{12,13}$. However, studies relating the prevalence of ventricular late potentials after transmural myocardial infarction with the affected wall show some conflicting results. Some studies have focused attention on the occurrence of ventricular late potentials in the first 12 months after transmural myocardial infarction when the myocardial remodeling process is still underway ${ }^{14}$. Data on the prevalence of ventricular late potentials in a late phase ( $>2$ years) of transmural myocardial infarction are very scarce. In this phase, the prevalence of ventricular late potentials reflects not only the natural 
selection of the patients surviving an infarction, but also represents a marker of the scar established ${ }^{15}$.

Our study was carried out to assess the prevalence of ventricular late potentials in a period greater than 2 years after transmural myocardial infarction, focusing on the initially affected wall.

\section{Methods}

We assessed 98 patients after their first transmural myocardial infarction (median of 924 days) who were consecutively referred to the Department of Electrocardiology and Arrhythmias of the Hospital Universitário Pedro Ernesto of the Universidade do Estado do Rio de Janeiro (HUPE-UERJ) from June 1995 to June 2000. These patients underwent surface electrocardiography, vector cardiography, one- and two-dimensional echocardiography, and signal-averaged electrocardiography, and were assessed in a retrospective case-control study adjusted for age and sex. The patients studied are part of the signal-averaged electrocardiography database (BDECG_AR) developed in the Department of Electrocardiology and Arrhythmias ${ }^{16}$.

A retrospective analysis was performed of patients' medical records, comprising clinical history, physical examination, and complementary examinations at the HUPEUERJ. Transmural myocardial infarctions were documented by the presence of necrotic regions on surface electrocardiographic leads related to the damaged wall, due to modifications in the vectorcardiographic loop and alterations in segmentary contractility, observed on two-dimensional echocardiography. Thirty-seven patients had anterior or anteroseptal transmural myocardial infarction (group A), and 61 patients had inferior or inferodorsal transmural myocardial infarction (group B) (table I) with an evolution greater than 2 years from the time of the initial acute event. All patients had sinus rhythm, left ventricular ejection fraction $>40 \%$, underwent one-dimensional echocardiography, and none of them had complete bundle-branch block on the surface electrocardiography. Patients with electrocardiographic signs indicating transmural myocardial infarction in other locations, such as anterior and inferior crossed myocardial infarction, isolated posterior myocardial in-

\begin{tabular}{|c|c|c|c|c|}
\hline \multicolumn{5}{|c|}{$\begin{array}{l}\text { Table I - Patient distribution, prevalence of ventricular tachycar- } \\
\text { dia, and ventricular late potentials in the groups studied }\end{array}$} \\
\hline & Group A & Group B & Group C & $\mathrm{p}^{\circledast}$ \\
\hline $\mathrm{N}$ & 37 & 61 & 43 & \\
\hline Age (years) & $56.3 \pm 13.0$ & $56.9 \pm 12.2$ & $59.7 \pm 11.4$ & NS \\
\hline Sex $(F / M)$ & $8 / 28$ & $17 / 44$ & $13 / 30$ & NS \\
\hline $\mathrm{VT}(\%)^{*}$ & $3(8.1 \%)$ & $8(13.1 \%)$ & $0(0 \%)$ & NS \\
\hline $\mathrm{VLP}-25 \mathrm{~Hz}^{* *}$ & $14(37.8 \%)^{\dagger}$ & $24(39.3 \%)^{\dagger \dagger}$ & $15(34.9 \%)^{\dagger}$ & NS \\
\hline $\mathrm{VLP}-40 \mathrm{~Hz}^{* *}$ & $10(27.0 \%)^{\dagger}$ & $22(36.1 \%)^{\dagger \dagger}$ & $11(25.6 \%)^{\dagger}$ & NS \\
\hline $\mathrm{VLP}-80 \mathrm{~Hz}{ }^{* *}$ & $11(29.7 \%)^{\dagger}$ & $35(57.4 \%)^{\dagger \dagger}$ & $19(44.2 \%)^{\dagger}$ & 0.008 \\
\hline \multicolumn{5}{|c|}{$\begin{array}{l}{ }^{*} \text { Prevalence of ventricular tachycardia; }{ }^{* *} \text { prevalence of ventricular late } \\
\text { potentials; }{ }^{\dagger} \text { comparison between the high-pass cut-off bands in the same } \\
\text { group, p=NS; }{ }^{\dagger \dagger} \text { comparison between the high-pass cut-off bands in the } \\
\text { same group, p }<0.05 ;{ }^{\oplus} \text { group A versus group B. }{ }^{\oplus} \text { Mean } \pm \text { SD. }\end{array}$} \\
\hline
\end{tabular}

farction, and isolated high lateral myocardial infarction were excluded. The medians of the times elapsed from the time of the acute event in groups A and B were, respectively, 1,095 and 848 days.

The prevalence of sustained monomorphic ventricular tachycardia was defined as: (1) presence of repetitive ventricular arrhythmia documented in the late phase of transmural myocardial infarction (median of 854 days) and (2) hemodynamic instability requiring electrical cardioversion. This prevalence and the respective distribution of ventricular late potentials were evaluated in groups A and B. All patients with sustained monomorphic ventricular tachycardia analyzed were using Vaughan-Williams group III antiarrhythmic drugs.

A group of 43 patients with ischemic myocardial disease and no previous clinically documented acute myocardial infarction (coronary artery disease, group C), ejection fraction $>40 \%$, no bundle-branch block, and similar distribution in regard to age and sex, was compared with groups A and B (table I). No patient in this group had alterations on the surface electrocardiogram, vector cardiogram, and echocardiogram compatible with transmural myocardial infarction.

The 12-lead surface electrocardiography was performed with $2 \mathrm{~N}$ amplification and velocity of $25 \mathrm{~mm} / \mathrm{s}$, using ECAPS 12 model Nyhon-Kohden equipment, with a maximum interval of 30 days from the signal-averaged electrocardiogram. Surface electrocardiography was used to evaluate the existence of intraventricular conduction disorders (complete bundle-branch blocks, defined as a QRS complex longer than 0.12 seconds) and to identify markers of old myocardial infarctions and their respective injured walls (pathological Q-waves defined as those with a duration > 0.04 seconds and amplitude $>2 \mathrm{~mm}$, on the leads accounting for the region). We assessed the leads from $V_{1}$ to $V_{4}$ in group $\mathrm{A}$, and the leads $\mathrm{D}_{2}, \mathrm{D}_{3}$, and $\mathrm{aVF}$ in group $\mathrm{B}$.

Vector cardiography was performed using Frank XYZ leads with $1507 \mathrm{c}$ Programmer model Hewlett Packard equipment, with the patient in the supine position, in a quiet environment, within a maximum interval of 30 days from the performance of signal-averaged electrocardiography. Vector cardiography was used to assess the existence of intraventricular conduction disorders and to identify old myocardial infarction markers and their respective injured walls. The diagnostic criteria used to analyze the vector cardiogram may be found in the literature ${ }^{17}$.

One- and two-dimensional echocardiography were used to respectively analyze left ventricular ejection fraction and segmentary contractility with the Apogee CX 200 (ATL, USA) within a maximum 30-day interval after the signal-averaged electrocardiography. The echocardiographic cuts and the analysis of the one- and two-dimensional images were performed by a trained observer using the routine procedures of the Echocardiography Department of the Cardiology Service of the HUPE-UERJ.

Identification of the injured region was based on the following criteria: (1) presence of pathological $Q$ waves in at 
least 2 leads that explore the same electrical region on the electrocardiogram; (2) loss of activation potentials with deviation of the vector cardiographic loop to the outside of the analyzed region; and (3) echocardiographic signs of segmentary alterations in the contractility of the analyzed region concordant with those found on vector cardiography and electrocardiography.

Signals of the signal-averaged electrocardiogram were obtained with the Predictor IIc (ART-Corazonix, USA) using Frank XYZ orthogonal leads, and they were coherent-averaged up to the noise level of $0.3 \mu \mathrm{V}$. The routine for signal acquisition was reported in a previous publication ${ }^{18}$.

Signal-averaged electrocardiogram underwent timedomain analysis through the magnitude vector, in the highpass cut-off frequencies of 25,40 , and $80 \mathrm{~Hz}$, with a 4-pole Butterworth bidirectional filter. The variables obtained from the vector magnitude were the duration of the filtered QRS (DUR[ms]), duration of the potentials in the terminal region of ventricular activation below $40 \mu \mathrm{V}$ (LAS $40[\mathrm{~ms}]$ ), and the value of the "root-mean-squared" of the potentials in the terminal $40 \mathrm{~ms}$ of ventricular activation (RMS $40[\mu \mathrm{V}])$. These variables were analyzed based on cut values for each highpass cut-off frequency according to Gomes et $\mathrm{al}^{19}$. The abnormal values for the variables analyzed DUR, LAS40, and RMS40 were, respectively, in the $25 \mathrm{~Hz}$ band, $>114 \mathrm{~ms}$, $>32 \mathrm{~ms}$, and $\langle 25 \mu \mathrm{V}$; in the $40 \mathrm{~Hz}$ band, $>114 \mathrm{~ms},>38 \mathrm{~ms}$, and $<20 \mu \mathrm{V}$; and in the $80 \mathrm{~Hz}$ band, $>107 \mathrm{~ms},>42 \mathrm{~ms}$, and $<17 \mu \mathrm{V}$. Identification of at least 2 abnormal variables in the vector magnitude defined the presence of ventricular late potentials in each frequency band.

Aiming at determining the best parameter to analyze the signal-averaged electrocardiogram, the patients with sustained monomorphic ventricular tachycardia after transmural myocardial infarction were analyzed in the highpass cut-off frequencies of 25,40 , and $80 \mathrm{~Hz}$, according to the above-cited criteria, and isolated, using the DUR or RMS40 parameters of the vector magnitude.

The diagnostic performance of the signal-averaged electrocardiogram was analyzed as an indicator of the presence of a myocardial lesion or a scar of a transmural myocardial infarction. This diagnostic capacity was assessed through the following indices: specificity (true negative examinations/total of control individuals), sensitivity (true positive examinations/total of patients), and total diagnostic accuracy (true negative examinations + true positive examinations /total of control + patients).

Transformations of variables have been reported in the literature to normalize asymmetric probability distributions. The variable RMS40 was transformed into a natural logarithm (Lnt) prior to analysis, due to its asymmetric probability distribution ${ }^{20}$. This procedure not only statistically normalizes the distribution, but also reduces data variability, concentrating them around the mean. The prevalence of ventricular late potentials and the mean values of the variables of the magnitude vector were compared between groups $\mathrm{A}$ and B for each high-pass cut-off band and analyzed, respectively, using the chi-square test to compare proportions and the two-tailed Student $t$ test to compare means. Odds ratio(OR) and its $95 \%$ confidence interval CI were assessed in the groups in which the prevalences of ventricular late potentials for a certain high-pass cut-off band had statistically significant differences continuous variables are expressed as mean \pm SD. Alpha error level was fixed at 0.05 . The following software was used for analysis: EPI info 6.04 version (CDC, USA), MS Excel 97 (Microsoft, USA), and Statgraphics Plus 4.0 version (Manugistic, USA).

\section{Results}

The prevalence of ventricular late potentials in groups $\mathrm{A}, \mathrm{B}$, and $\mathrm{C}$ according to the high-pass cut-off bands is shown in table I. In group B, the prevalence of ventricular late potentials was higher at $80 \mathrm{~Hz}(57.4 \%)$ than in the other bands $\left(39.3 \%\right.$ at $25 \mathrm{~Hz}$ and $36.1 \%$ at $\left.40 \mathrm{~Hz}, \chi^{2}=6.51, \mathrm{p}=0.04\right)$. On the other hand, at $80 \mathrm{~Hz}$, the prevalence of ventricular late potentials was higher in group B than in group A $\left[\chi^{2}=7.07, \mathrm{p}=0.008\right.$ (table I) and $\mathrm{OR}=3.18,(95 \% \mathrm{CI} 1.24-8.42)$, $\left.\chi^{2}=6, \mathrm{p}=0.01\right]$.

The distribution of patients with sustained monomorphic ventricular tachycardia did not show statistically significant differences between groups $\mathrm{A}$ and $\mathrm{B}\left(\chi^{2}=0.19\right.$, $\mathrm{p}=\mathrm{NS}$ ).

The vector magnitude parameters for each group and respective high-pass cut-off bands are shown in table II. The variables in groups $A$ and $C$ showed no significant differences. However, LAS40 was wider in group B than in group $\mathrm{A}$ in the $40 \mathrm{~Hz}$ and $80 \mathrm{~Hz}$ bands (respectively, $\mathrm{t}=2.67$, $\mathrm{p}=0.004$ and $\mathrm{t}=2.26, \mathrm{p}=0.02$ ).

The diagnostic parameters of sensitivity, specificity, and total accuracy, which were analyzed as indicators of myocardial lesions, are shown in table III. The comparisons of the variables DUR, RMS40 Lnt, and LAS40 among the patients with sustained monomorphic ventricular tachycar-

\begin{tabular}{|c|c|c|c|}
\hline \multicolumn{4}{|c|}{$\begin{array}{l}\text { Table II - Magnitude vector parameters according to the study } \\
\text { group and the cut-off band of the filter used for analysis }\end{array}$} \\
\hline \multicolumn{4}{|c|}{ Group A } \\
\hline & DUR (ms) & RMS40 Lnt ${ }^{+}$ & LAS40 (ms) \\
\hline $25 \mathrm{~Hz}$ filter $^{\dagger \dagger}$ & $103.7 \pm 13.9$ & $3.5 \pm 1.0$ & $30.5 \pm 14.8$ \\
\hline $40 \mathrm{~Hz}$ filter & $98.0 \pm 13.7 *$ & $3.5 \pm 1.0$ & $31.9 \pm 13.3^{*}$ \\
\hline $80 \mathrm{~Hz}$ filter & $97.0 \pm 13.9^{*}$ & $2.7 \pm 1.0$ & $40.4 \pm 14.2 *$ \\
\hline \multicolumn{4}{|c|}{ Group B } \\
\hline & DUR (ms) & $\mathrm{RMS} 40 \mathrm{Lnt}^{\dagger}$ & LAS40 (ms) \\
\hline $25 \mathrm{~Hz}$ filter & $107.0 \pm 12.9$ & $3.5 \pm 0.8$ & $29.0 \pm 11.9$ \\
\hline $40 \mathrm{~Hz}$ filter & $106.7 \pm 14.3^{*}$ & $3.2 \pm 0.8$ & $36.2 \pm 14.0 *$ \\
\hline $80 \mathrm{~Hz}$ filter & $103.3 \pm 13.0^{*}$ & $2.5 \pm 0.9$ & $47.7 \pm 14.0^{*}$ \\
\hline \multicolumn{4}{|c|}{ Group C } \\
\hline & DUR (ms) & $\mathrm{RMS} 4 \mathrm{Lnt}^{\dagger}$ & LAS40 (ms) \\
\hline $25 \mathrm{~Hz}$ filter & $108.8 \pm 15.5$ & $3.6 \pm 0.8$ & $30.1 \pm 10.3$ \\
\hline $40 \mathrm{~Hz}$ filter & $103.2 \pm 13.3$ & $3.3 \pm 0.9$ & $33.5 \pm 12.7$ \\
\hline $80 \mathrm{~Hz}$ filter & $100.6 \pm 14.9$ & $2.6 \pm 0.7$ & $39.5 \pm 13.0$ \\
\hline \multicolumn{4}{|c|}{$\begin{array}{l}{ }^{\dagger} \text { Lnt- natural logarithmic transformation; }{ }^{\dagger}{ }^{\dagger} \text { high-pass cut-off frequency } \\
\text { of the filter used to analyze the magnitude vector; }{ }^{*} \mathrm{p}<0.05 \text { (group A } \\
\text { versus group B). }\end{array}$} \\
\hline
\end{tabular}


dia in the late period after acute myocardial infarction in groups $A$ and $B$ are shown in table IV. Except for the variable DUR at $25 \mathrm{~Hz}$, all other variables showed statistically significant differences (table IV). In regard to episodes of sustained monomorphic ventricular tachycardia, no significant differences were observed in the prevalence of ventricular late potentials between groups A and B. In group A, no patient with sustained monomorphic ventricular tachycardia was identified with ventricular late potentials at $25 \mathrm{~Hz}$ and $40 \mathrm{~Hz}$ high-pass cut-off bands, both using conventional definitions and analyzing RMS40. At $80 \mathrm{~Hz}$ band, ventricular late potentials were identified in 1 out of 3 $\left(\chi^{2}=0.01 ; \mathrm{p}=0.99\right)$ patients, using conventional definitions; however, when analyzing RMS40, 2 out of $3\left(\chi^{2}=0.75 ; p=0.4\right)$ patients met the criteria for ventricular late potentials. In group B patients with sustained monomorphic ventricular tachycardia, ventricular late potentials were identified in 4 out of 8 patients $\left(\chi^{2}=3 ; \mathrm{p}=0.08\right)$ at $40 \mathrm{~Hz}$ and $80 \mathrm{~Hz}$ high-pass cut-off bands using the conventional definitions, in 5 out of 8 patients at $40 \mathrm{~Hz}$ high-pass cut-off band $\left(\chi^{2}=4.65\right.$; $\mathrm{p}=0.03$ ), and in 6 out of 8 patients at $80 \mathrm{~Hz}$ high-pass cut-off band, the 2 latter being evaluated with the isolated RMS40 variable $\left(\chi^{2}=6.67 ; p=0.01\right)$. In the remaining high-pass cutoff bands, the presence of ventricular late potentials

\begin{tabular}{|c|c|c|c|}
\hline \multicolumn{4}{|c|}{$\begin{array}{l}\text { Table III - Diagnostic value of VLP according to the study group } \\
\text { and the cut-off band of the filter used for analysis }\end{array}$} \\
\hline & $25-250 \mathrm{~Hz}$ & $40-250 \mathrm{~Hz}$ & $80-250 \mathrm{~Hz}$ \\
\hline Specificity (group C) & $65.1 \%$ & $74.4 \%$ & $55.8 \%$ \\
\hline Sensitivity (group A) & $37.8 \%$ & $27 \%$ & $29.7 \% *$ \\
\hline Sensitivity (group B) & $39.3 \%$ & $36.1 \%$ & $57.4 \% *$ \\
\hline Sensitivity (all) ${ }^{\dagger}$ & $40 \%$ & $34.5 \%$ & $50 \%$ \\
\hline Total accuracy (group A) & $40.4 \%$ & $40.4 \%$ & $35.7 \% *$ \\
\hline Total accuracy (group B) & $50 \%$ & $51.9 \%$ & $56.7 \% *$ \\
\hline Total accuracy (all) $)^{\dagger}$ & $47.1 \%$ & $45.8 \%$ & $51.6 \%$ \\
\hline
\end{tabular}

\begin{tabular}{|c|c|c|c|}
\hline \multicolumn{4}{|c|}{$\begin{array}{l}\text { Table IV - Comparison of the magnitude vector variables in } \\
\text { patients with sustained monomorphic ventricular tachycardia in } \\
\text { groups A and B according to the high-pass cut-off frequency of } \\
\text { the filter used }\end{array}$} \\
\hline & Group A & Group B & $\mathrm{p}$ \\
\hline DUR $25 \mathrm{~Hz}^{*}(\mathrm{~ms})$ & $112 \pm 11.5$ & $111.2 \pm 13.9$ & NS \\
\hline DUR $40 \mathrm{~Hz}(\mathrm{~ms})$ & $107.7 \pm 12.9$ & $120.2 \pm 16.5$ & $<0.001$ \\
\hline DUR $80 \mathrm{~Hz}(\mathrm{~ms})$ & $102.8 \pm 17.1$ & $112.8 \pm 13.3$ & 0.003 \\
\hline LAS40 $25 \mathrm{~Hz}(\mathrm{~ms})$ & $22.8 \pm 11.4$ & $34.5 \pm 16.4$ & $<0.001$ \\
\hline LAS $4040 \mathrm{~Hz}(\mathrm{~ms})$ & $27.5 \pm 6.1$ & $52.7 \pm 15.6$ & $<0.001$ \\
\hline LAS40 80Hz (ms) & $36.7 \pm 12.4$ & $55 \pm 12.9$ & $<0.001$ \\
\hline $\begin{array}{l}\text { RMS } 40 \text { Lnt } 25 \mathrm{~Hz} \\
{[\operatorname{Ln}(\mu \mathrm{V})]}\end{array}$ & $3.7 \pm 0.5$ & $3.4 \pm 0.9$ & 0.04 \\
\hline $\begin{array}{l}\text { RMS40 Lnt } 40 \mathrm{~Hz} \\
{[\operatorname{Ln}(\mu \mathrm{V})]}\end{array}$ & $3.6 \pm 0.4$ & $2.8 \pm 1.3$ & $<0.001$ \\
\hline $\begin{array}{l}\text { RMS40 Lnt } 80 \mathrm{~Hz} \\
{[\operatorname{Ln}(\mu \mathrm{V})]}\end{array}$ & $2.8 \pm 0.4$ & $2.3 \pm 1.1$ & 0.01 \\
\hline
\end{tabular}

showed no statistically significant results in the definitions analyzed in both groups.

\section{Discussion}

The introduction of signal-averaged electrocardiography as a noninvasive diagnostic method in cardiology enabled the identification of micropotentials originating in electrically unstable regions of the injured myocardium, widening the horizons and increasing the chances of understanding the bioelectrical phenomena originating in the heart ${ }^{21}$.

The characteristics related to myocardial electrical conduction after myocardial infarction depend both on the damaged area and on the intensity of the alteration in its surrounding tissues. Therefore, the location of the myocardial lesion is expected to influence the presence of ventricular late potentials on signal-averaged electrocardiography. The correlation between the lesion and ventricular late potentials depends on clinical factors related to the disease, on local electrophysiological factors (ischemia), and on the type of processing applied to the acquired electrocardiographic signals. In this context, we highlight the use of drugs that spare the myocardium in the acute phase ${ }^{15,22}$, the start of depolarization of the affected site in relation to the total duration of ventricular activation, the type of filter used to analyze the events ${ }^{19,23}$, and the instantaneous heart rate ${ }^{4,24}$. Features like the low ability to characterize the infarct site based on the isolated analysis of surface electrocardiography should be considered at the time of group division, because it may lead to inconsistent results ${ }^{10}$.

Ventricular late potentials have been analyzed in several frequency bands aiming not only to identify the frequency content of these signals, but also to investigate the region of the frequency spectrum that allows its identification with a higher diagnostic efficiency ${ }^{19,20}$. This type of investigation is mainly justified from the viewpoint of electrocardiographic signal processing, because high-pass cut-off filters with lower cut-off frequencies $(25 \mathrm{~Hz})$ preserve the high-energy QRS characteristics, while higher cut-off frequencies $(80 \mathrm{~Hz})$ remove the high energies and preserve high frequency signals originating in small groups of myocardial fibers in regions of slow and fragmented conduction.

In our study, the increase in the global prevalence of ventricular late potentials was evidenced only in the highpass cut-off filter of $80 \mathrm{~Hz}$ (tab. I) and was accompanied by a significant widening of the LAS40 variable in the $40 \mathrm{~Hz}$ and $80 \mathrm{~Hz}$ high-pass cut-off bands (tab. II). An odds ratio of 3.18 $(\mathrm{p}=0.01)$ indicates that individuals after a transmural myocardial infarction of the inferior wall triple their chance of having ventricular late potentials on the time-domain analysis of the signal-averaged electrocardiogram as compared with individuals after transmural myocardial infarction of the anterior wall in the same period.

The distribution of ventricular late potentials according to the region affected in the acute event was analyzed by Gomes et $\mathrm{al}^{25}$ in patients with myocardial infarction within 1 year of evolution, and they found results similar to 
ours. Rosas et $\mathrm{al}^{10}$ analyzed patients with anterior and inferior acute myocardial infarction aiming to assess the relation between coronary artery patency and the presence of ventricular late potentials. These authors found differences in the results of the signal-averaged electrocardiogram between the 2 groups, both in the time and frequency domains. However, Vatterott et al ${ }^{26}$, using a high-pass cut-off band of $40 \mathrm{~Hz}$, found no difference in the distribution of ventricular late potentials after acute myocardial infarction related to the damaged wall. Results similar to those observed in our study were found by Lander et $\mathrm{al}^{27}$ and Savard et $\mathrm{al}^{28}$.

The correlation between ventricular late potentials and sustained monomorphic ventricular tachycardia has been widely discussed in the literature ${ }^{2-3,13,18}$. One week after transmural myocardial infarction, approximately $30 \%$ to $60 \%$ of patients have ventricular late potentials on signal-averaged electrocardiography. However, within the first year after transmural myocardial infarction, both sensitivity and the positive predictive value of ventricular late potentials for sustained monomorphic ventricular tachycardia or sudden death are very low. This fact indicates that ventricular late potentials are better markers of structurally established myocardial lesions, which may eventually become a substrate for arrhythmias through a reentry mechanism, than proper clinical markers of repetitive ventricular arrhythmia. Considering the presence of ventricular late potentials after transmural myocardial infarction, the mechanisms triggering repetitive arrhythmia are not necessarily related to the presence of these signals ${ }^{11}$. We speculate that other factors, such as unidirectional block ${ }^{11}$ and an instantaneous heart rate ${ }^{24}$, associated with alterations in the pattern of sympathovagal autonomic myocardial modulation may contribute to the transformation of the substrate. In group B patients with documented episodes of sustained monomorphic ventricular tachycardia, all variables of the vector magnitude analyzed had durations and voltages significantly lower and more prolonged than those in group A patients for all cut-off bands, except for the DUR variable at $25 \mathrm{~Hz}$. The prevalence of ventricular late potentials in group A did not register significant values, but, in group B, this prevalence was significantly high at $40 \mathrm{~Hz}$ and $80 \mathrm{~Hz}$ cut-off bands using the conventional definitions and at $40 \mathrm{~Hz}$ and $80 \mathrm{~Hz}$ cut-off bands assessed on the isolated RMS40 variable. Considering the reduced number of elements in each group, these findings support the electrophysiological principle that the ventricular activation of the anteroseptal regions occurs before that occurring in the inferobasal regions. This strengthens the hypothesis that fragmented potentials originating in the first regions have their time course parallel to ventricular activation, being covered during depolarization, while those originating later go beyond ordinary ventricular activation reaching the ST-segment.

A lower prevalence of ventricular late potentials is expected in chronic coronary artery disease rather than after transmural myocardial infarction, because no anatomical substrate is supposed to exist in that disease. However, the high prevalence of ventricular late potentials in group C, similar to that observed in patients with anterior transmural myocardial infarction (group A), suggests that chronic ischemia may cause structural myocardial lesions compatible with the concept of ischemic cardiomyopathy, which are not detected using some conventional methods ${ }^{29}$.

All patients with episodes of sustained monomorphic ventricular tachycardia were using Vaughan-Williams group III antiarrhythmic drugs. Even though these drugs prolong ventricular late potentials ${ }^{30,31}$, their expected effects were considered not to influence the comparative results, because they were distributed in both groups in a similar manner. The use of thrombolytic drugs, the use of invasive procedures to identify the culprit coronary artery, and the prevalence of episodes of aborted sudden death and of sustained monomorphic ventricular tachycardia in the acute phase of transmural myocardial infarction were not investigated in this study. Even though the patients analyzed constituted a group of late survivors of transmural myocardial infarction, when the anatomical spectrum of myocardial lesions undergo significant modifications, we consider that the impact of these variables on the results observed requires further investigation.

The prevalence of ventricular late potentials observed in a late phase ( $>2$ years) after the first transmural myocardial infarction is greater in the inferior-inferodorsal wall lesions than in the anterior-anteroseptal wall lesions. The identification of these arrhythmogenic potentials is significantly influenced by the high-pass cut-off band used for the timedomain analysis of the signal-averaged electrocardiogram. In groups of patients after transmural myocardial infarction with documented clinical episodes of severe repetitive ventricular arrhythmias, ventricular late potentials are betteridentified at elevated cut-off frequencies for both anterior-anteroseptal wall lesions and inferior-inferodorsal wall lesions, confirming the high-frequency nature of these signals.

\section{Acknowledgments}

We thank Professor Justiniano Simões Lopes for reviewing this manuscript and for important contributions.

\section{References}

1. Berbari EJ, Sherlag BJ, Hoper R, Lazzara R. Recordings from the body surface of arrhythmogenic ventricular activity during ST segment. Am JCardiol 1978; 41: 697-702.
2. Breithardt G, BeckerR, SeipelL, et al. Non-invasive detection of late potentials in man: a new marker of ventricular tachycardia. Eur Heart J 1981;2:1-11.

3. Nogami A, Iesaka Y, Akiyama J, et al. Combined use of time and frequency domain 
variables in signal-averaged ECG as a predictor of inducible sustained monomorphic ventricular myocardial infarction. Circulation 1992; 86: 780-9.

4. Barbosa PRB. A signal-averaging system for surface ECG signal analysis. Phys Med Biol 1994: 39:412.

5. Barbosa PRB, BarbosaEC, Ginefra P. Avaliação do ruído do ecg-ar em pacientes com infarto agudo do miocárdio. Estudo preliminar. RevSOCERJ 1997:10(supl A): 28 .

6. Barbosa PRB. Análise dos potenciais tardios da ativação ventricular baseada no histograma de intervalos RR modais. Tese de Mestrado, Programa de Engenharia Biomédica, COPPE/UFRJ, Rio de Janeiro, Brasil, 1997.

7. Dopico LR, Nadal J, Infantosi AFC. Análise dos potenciais tardios do eletrocardiograma de alta resolução de pacientes chagásicos usando a média ponderada. Rev Bras Eng Biomed 2000; 16: 49-59.

8. KucharDL, Thorburn CW, SammelNL. Late potentials detected after myocardial infarction: natural history and prognostic significance. Circulation 1986; 74: $1280-9$

9. Gomes JA, Mehra R, Barreca P, el-Sherif N, Hariman P, Holtzman R. Quantitative analysis of the high frequency components of the signal-averaged QRS complex in patients with acute myocardial infarction: a prospective study. Circulation 1985; 72:105-11.

10. Rosas M, Hermosillo AG, Infante O, Kuri J, Cardenas M. Relationship between the site of a myocardial infarction and signal-averaged electrocardiogram indices. Int J Cardiol 1998; 63: 129-40.

11. El-Sherif N, Gough WB, Restivo M. Electrophysiologic correlates of ventricular late potentials. In: El-Sherif N, Turitto G (eds): High-Resolution Electrocardiography. Mount Kisco, NY: Futura Publishing Co., Inc., 1992: 279-98.

12. Gomes JA, Horowitz SF, Millner M, Mochec J, Winters SL, Barreca P. Relation of late potentials to ejection fraction and wall motion abnormalities in acute myocardial infarction. Am J Cardiol 1987; 59: 1071-4.

13. Gomes JA, Winters SL, Stewart D, Horowitz S, Millner M, Barreca P. A new noninvasive index to predict sustained ventricular tachycardia and sudden death in the first year after myocardial infarction: based on signal-averaged electrocardiogram, radionuclide ejection fraction and Holter monitoring. J Am Coll Cardiol 1987; 10:349-57.

14. Sakai $Y$, Tsunoda K, Ishibashi I, et al. Time course of left ventricular remodeling after myocardial infarction: a two-dimensional echocardiographic study. Jpn Circ J 2000; 64: 421-9.

15. Zimmermann M,Sentici A, Adamec R, et al.Long-term prognostic significance of ventricular late potentials after a first acute myocardial infarction. Am Heart J 1997; 134: 1019-28.

16. De Sousa MO. Oeletrocardiograma de alta resolução na fase crônica da cardiopatia isquêmica: importância de diferentes bandas-passantes na identificação de potenciais tardios da ativação ventricular. Tese de mestrado, FCM-UERJ, Rio de Janeiro, Brasil, 2000.

17. Tranchesi J. Eletrocardiograma Normal e Patológico: Noções de Vectorcardiografia. São Paulo: Atheneu Editora, 1967.
18. BarbosaEC, Barbosa PRB, Ginefra P, Albanesi-Fo FM. O eletrocardiograma de alta resolução no domínio da frequiência: utilização técnicas estatísticas de correlação espectral para a identificação de pacientes com taquicardia ventricular monomórfica sustentada. Arq Bras Cardiol 1998;71:595-9.

19. Gomes JA, Winters SL, StewartD, Targonski A, BarrecaP. Optimal bandpass filters for time-domain analysis of the signal-averaged electrocardiogram. Am J Cardiol 1987; 60: 1290-8.

20. Caref EB, Turitto G, Ibrahim BB, et al. Role of bandpass filters in optimizing the value of the signal-averaged electrocardiogram as a predictor of the results of programmed stimulation. Am J Cardiol 1989; 64: 16-26.

21. Scherlag BJ, Lazzara R. High-Resolution Electrocardiography: Historical Perspectives. In: El-Sherif N, Turitto G (eds): High-Resolution Electrocardiography. Mount Kisco, NY: Futura Publishing Co. Inc., 1992: 3-20.

22. Hochman JS, Buller CE, Sleeper LA, et al. Cardiogenic shock complicating acute myocardial infarction - etiologies, management and outcome: a report from the SHOCK Trial Registry. Should we emergently revascularize occluded coronaries for cardiogenic shock? J Am Coll Cardiol 2000; 36 (3 suppl A): 1063-70.

23. Barbosa PRB, Barbosa EC, Ginefra P, Nadal J. Butterworth bi-directional and Bispec $^{\mathrm{TM}}$ filters in the assessment of ventricular late potentials: a comparative study.Comput Cardiol 1999;26: 579-82.

24. Barbosa PRB, Barbosa Filho J, Sá CAM, Nadal J. Assessment of ventricular late potentials in HIV positive patients based on the RR interval histogram. Comput Cardiol 1999; 26: 327-30.

25. Gomes JA, Winters SL, Martinson M, Mochec J, Stewart G, Jargoriski A. The prognostic significance of quantitative signal-averaged variables relative to clinical variables, site of myocardial infarction, ejection fraction and ventricular premature beats: a prospective study. J Am Coll Cardiol 1989; 13: 377-84.

26. Vatterott PJ, Bailey KR, Hammil CS. Improving the predictive ability of the signal-averaged electrocardiogram with a linear logistic model incorporating clinical variables. Circulation 1990; 81: 797-804

27. Lander P, Gomis P, Goyal R, et al. Analysis of abnormal intra-QRS potentials: improved value for arrhythmogenic events with the signal-averaged electrocardiogram.Circulation 1997; 95: 1386-93.

28. Savard P, Rouleau JL, Ferguson J. Risk stratification after myocardial infarction using signal-averaged electrocardiographic criteria adjusted for sex, age, and myocardial infarction location. Circulation 1997; 96: 202-13.

29. Tamura K, Tsuji H, Masui A, et al. Prevalence, resolution and determinants of late potentials in patients with unstable angina and left ventricular wall motions abnormalities. Am Heart J 1996; 131: 731-5.

30. Telichowski A, Banasiak W, Bobak J, et al. The effect of long term use of amiodarone hydrochloride on time and frequency domain parameters of signal averaged electrocardiogram in patients with ischemia heart disease. Pol Merkuriusz Lek 1997; 2: 378-81.

31. Kubik L, MichalkiewiczD. Influence of amiodarone on results of the signal-averaged electrocardiogram. Pol Arch Med Wewn 1996; 95: 299-306. 